\title{
Further Studies on the Isolation of Proteolytic Bacteria from the Sheep Rumen
}

\author{
By T. H. BLACKBURN AND P. N. HOBSON \\ The Rowett Research Institute, Bucksburn, Aberdeen
}

(Received 27 March 1962)

\section{SUMMARY}

A survey of the proteolytic bacteria present in the rumens of sheep on different kinds of diets has been made, with special emphasis on the isolation of anaerobic types. The results suggest that proteolytic activity is not confined to a single kind of rumen bacterium, but that it is a variable property possessed by strains of many kinds of bacteria which can be active in the breakdown of other feedstuff constituents. The properties of the bacteria isolated are given.

\section{IN'TRODUCTION}

In a previous paper (Blackburn \& Hobson, $1960 a$ ), it was shown that the microorganisms of sheep rumen contents readily hydrolysed casein and that this activity was associated both with the protozoa and the large and small bacteria. The results of attempts to isolate actively proteolytic bacteria, however, resulted in the isolation of only a limited number of types, most of which were facultative anaerobes (Blackburn \& Hobson, 1960b). Although these were present in numbers which seemed to be quite comparable with the highest dilutions of rumen contents from which a mixed proteolytic flora could be grown, it was felt that they represented only a part of the proteolytic bacteria present in the rumen. The isolated bacteria did not include representatives of the strictly anaerobic rumen bacteria which have been shown to be active in the breakdown of feedstuff carbohydrates and lipids and which were present in the proteolytic suspensions of bacteria, but it was shown that mixed cultures containing these types of bacteria could be grown in a caseincontaining medium and that the casein was hydrolysed in some of the cultures (Blackburn \& Hobson, $1960 b, c$ ). The present work describes the results of experiments directed towards the isolation and classification of types of proteolytic bacteria other than those previously described.

\section{METHODS}

\section{Media}

In the previous work different kinds of media were tested for growth of proteolytic bacteria and it was on the basis of these results that the media used here were prepared. All media, except those used to detect growth without $\mathrm{CO}_{2}$, were thoroughly gassed with oxygen-free $\mathrm{CO}_{2}$ during preparation and dispensing, and all manipulations were carried out under a stream of oxygen-free $\mathrm{CO}_{2}$ using techniques based on those of Hungate (1950). Media used during the preliminary tests with cysteine as 
reducing agent, and resazurin as oxidation-reduction indicator, were reduced to below the Eh value needed for production of the colourless form of resazurin and generally had an oxidation-reduction potential measured between platinum and calomel electrodes of $c .-\mathbf{3 7 0} \mathrm{mV}$. The more reduced media (using cysteine and dithionite as reducing system) were reduced to the point where phenosafranine was just colourless. The measured reduction potential of these media was about -410 to $-470 \mathrm{mV}$.

\section{General constituents of the media}

Salts solutions. Solution (a) contained (g./l.): $\mathrm{KH}_{2} \mathrm{PO}_{4}, 3 \cdot 0 ;\left(\mathrm{NH}_{4}\right)_{2} \mathrm{SO}_{4}, 6 \cdot 0$; $\mathrm{NaCl}, 6 \cdot 0 ; \mathrm{MgSO}_{4}, 0 \cdot 6 ; \mathrm{CaCl}_{2}, 0 \cdot 6$. Solution (b) contained (g./l.): $\mathrm{K}_{2} \mathrm{HPO}_{4}, \mathbf{3 \cdot 0}$. Rumen fluid was prepared by straining rumen contents (freshly obtained from a hay and grass-fed sheep) through gauze and centrifuging at $62,000 \mathrm{~g}$ for $10 \mathrm{~min}$. The clear liquid was kept for not more than a few days at $2^{\circ}$ before use.

Bicarbonate-dithionite solution. Dithionite was added, as a small volume of a concentrated solution $(6 \%, \mathrm{w} / \mathrm{v})$ in boiled water, to a sterile $10 \%(\mathrm{w} / \mathrm{v})$ solution of $\mathrm{NaHCO}_{3}$. The mixed solution was gassed with $\mathrm{CO}_{2}$ and a portion added to the medium to bring the final concentrations to 0.5 and $0.003 \%$ respectively of $\mathrm{NaHCO}_{3}$ and dithionite.

'Sugars' (including carbohydrates, alcohols and acids) were the usual commercially available reagent grades, the xylan was the xylan no. 3 used by Howard, Jones \& Purdom (1960). Cellulose was prepared from Whatman no. 1 filter-paper ground in a ball mill to a fine powder. Carboxymethyl cellulose was Cellofas B, low viscosity (I.C.I. Ltd). For isolation of bacteria, cellulose, xylan, carboxymethyl cellulose and malt extract were incorporated into the medium before autoclaving. Other carbohydrates were added as concentrated sterile filtered solutions, except for starch which was an autoclaved solution.

Casein was Glaxo casein C (Glaxo, Ltd, Greenford, Middlesex). This was acid precipitated, washed with water and dissolved in dilute $\mathrm{NaOH}$, neutralized and the solution freeze-dried to give an easily soluble powder, which was added as a solution to the medium before autoclaving.

Other constituents. Yeast extract was 'Difco' brand (Bacto Laboratories, Detroit, U.S.A.). Tryptose was 'Bacto' brand (Bacto Laboratories, Detroit, U.S.A.). Malt extract was 'Bacto' brand (Bacto Laboratories, Detroit, U.S.A.). L-Cysteine hydrochloride was from L. Light, Ltd, Colnbrook, Bucks.

Media for isolations. The media used for the isolations described here were basically similar and the constituents and preparation of the medium for isolations from sheep 74 and 190 only will be described in detail. This medium contained per $100 \mathrm{ml}$. : salts solution (a) $15 \mathrm{ml}$.; salts solution (b) $15 \mathrm{ml}$.; phenosafranine, 0.0001 g.; cysteine hydrochloride, $0.05 \mathrm{~g}$.; casein, $0.5 \mathrm{~g}$.; rumen fluid, $10 \mathrm{ml}$.; tryptose, 0.3 g.; agar, $2.5 \mathrm{~g}$.; water, $55 \mathrm{ml}$. These constituents were added as solids or solutions, mixed and gassed with $\mathrm{CO}_{2}$ and autoclaved at $120^{\circ}$ for $15 \mathrm{~min}$. under $\mathrm{CO}_{2}$ in a flask fitted with a bunsen valve and a stoppered side tube. For addition of other medium constituents or dispensing of medium the bunsen valve was removed and a syringe inserted through the tubing to which the valve had been attached. A brisk stream of $\mathrm{CO}_{2}$ was meanwhile passed through the side tube and flowed out around the syringe ensuring anaerobic conditions. After addition of the bicarbonate-dithionite 
solution ( $5 \mathrm{ml}$., see above) and any carbohydrate solution (final carbohydrate concentration was usually $0.5 \%(\mathrm{w} / \mathrm{v})$ ) necessary, the medium at $50^{\circ}$ was dispensed into tubes under $\mathrm{CO}_{2}$ by means of hypodermic syringes or a laboratory-made dispensing apparatus for use under $\mathrm{CO}_{2}$. Tenfold dilutions of rumen fluid were made under $\mathrm{CO}_{2}$ in a solution prepared exactly like the medium, but omitting the agar and carbohydrate. One half millilitre portions of the diluted rumen fluid were added to $4.5 \mathrm{ml}$. of medium in $6 \times \frac{5}{8}$ in. test tubes under $\mathrm{CO}_{2}$, the tubes tightly stoppered with rubber bungs and rolled under cold water. For liquid media the agar was omitted, but the cultures were still incubated in test tubes as above, at $38^{\circ}$.

Media for biochemical reactions. For determination of fermentation and other reactions of the bacteria the isolation medium was appropriately modified. Unless the degree of hydrolysis of casein was to be determined this was omitted from the media and yeast extract $(0.3 \%, \mathrm{w} / \mathrm{v})$ was added. Growth without $\mathrm{CO}_{2}$ was tested in media prepared and dispensed under oxygen-free nitrogen and with bicarbonate replaced by phosphate.

Motility was looked for in young cultures containing only $0.1 \%$ glucose or maltose, and films for flagella staining made from these same cultures.

Analytical methods. The degree of proteolysis in liquid media was determined with biuret reagent in a manner similar to that used in the previous work (Blackburn \& Hobson, $1960 \mathrm{~b}$ ). Less than about $10 \%$ hydrolysis of casein could not be determined very accurately by this method. Urea hydrolysis was determined by estimating the ammonia liberated in suitable portions of the cultures using the method of Conway (1957). Volatile fatty acids (VFA) and succinic acid were identified by paper chromatography by suitable methods, uninoculated media being used as controls.

Sheep and sampling procedures. The two sheep used for the main isolations, 74 and 190 , were fed $700 \mathrm{~g}$. hay $+350 \mathrm{~g}$. concentrates (fish meal, linseed meal, oat bran, maize meal) and $900 \mathrm{~g}$. hay $+450 \mathrm{~g}$. grass cubes, respectively, per day, fed in two lots at 7 a.m. and 4 p.m. Sheep 100 was fed 900 g. hay and $450 \mathrm{~g}$. concentrates per day in two feeds. Sheep 6 and 477 were given the partially synthetic soluble casein-containing diet previously described. (Diet $a$, Blackburn \& Hobson, 1960 c.) Sheep 5 was fed $900 \mathrm{~g}$. hay per day in two feeds.

Samples were taken via a rumen cannula, rapidly strained to remove coarse debris, and diluted and cultured as soon as possible after this. Generally, samples were taken about $3 \mathrm{hr}$. after the morning feed.

\section{RESULTS}

During a series of initial experiments many variations in the constituents and methods of reduction of the media were tested, as was the time of incubation needed to detect proteolysis. The results obtained, which relate to the problems of the best medium for growth of rumen bacteria, are not given here but may be obtained from the authors. Liquid and solid media were also compared. Although proteolysis on solid media was not always easy to detect and did not always correspond with the activity in corresponding liquid media, it proved difficult to isolate pure proteolytic strains from mixed liquid cultures and so most of the isolations were made by culturing dilutions of rumen fluid in solid media, picking off a selection of colonies 
which seemed to show some change in the medium, and testing these for proteolytic activity in liquid media initially and at intervals after purification by dilution and subculture. In order to culture as many types of bacteria as possible it was finally decided to use the same basic medium with a wide variety of carbohydrates as energy sources and to survey the proteolytic bacteria in two sheep (74 and 190) on two basic types of diet, as well as in the other sheep available. The isolations were carried out over a period of some months, but the types of bacteria in the rumens seemed to be stable over this time. All the bacteria isolated could thus be taken to be stable constituents of the flora and not transient types introduced, for example, with the feed. Only the proteolytic bacteria growing in the highest dilutions in each test were subcultured and examined.

A wide range of properties of the bacteria were tested as detailed information on the properties of rumen bacteria from other than a few sources (principally cattle) is lacking. Also, since the properties of the individual strains of the bacteria which have been tentatively classified often seem to be very variable, a large amount of data on the bacterial properties would seem to be necessary before a comprehensive classification can be made. However, to economize in space complete fermentation reactions of the isolates are not given in the tables (full details may be obtained from the authors). Apart from the properties mentioned in Table 1, fermentation of the following 'sugars' was tested: arabinose, rhamnose, mannose, galactose, mannitol, dulcitol, sucrose, trehalose, melibiose, raffinose, $\alpha$-methylglucoside, aesculin, dextrin, glycogen, sorbose, sorbitol, inositol, succinate, acetate. The method of numbering the isolated strains is as follows. Number of host animal, carbohydrate in isolation medium, log. 10 dilution of rumen contents from which isolation was made (number of colonies of this organism in the dilution), i.e. 74 cell 7 (2) was an organism from sheep 74, isolated in a medium containing cellulose and occurring as two colonies in the $1 / 10^{7}$ dilution of rumen contents. The abbreviations used for the carbohydrates in the isolation media are given with the tables. A letter ' $a$ ' or ' $b$ ' has been added to the designation in some cases merely to distinguish between two isolates otherwise bearing the same number.

\section{Properties of bacteria isolated from sheep fed different diets}

The isolates have been grouped according to their properties and some tentative classifications made on the basis of the named groups of bacteria isolated from cattle by American workers. As only a few strains of some of the named organisms have been described in detail and the properties of individual strains often vary considerably, it has been found difficult to classify accurately some of the isolates described here, but connexions with the named bacteria are mentioned. Since similar bacteria were isolated from all animals they have not been grouped according to the source. Unless otherwise mentioned, all isolates were strict anaerobes.

Group 1. Bacteroides amylophilus. This group includes isolates 6malt7, 74maltE6, 74gluc8(2), 5xmc7, 5xmc8, 47gluc8, 47cellob9 47gluc8a, 47cellob8 (malt = maltose; maltE = malt extract; glu = glucose; $x m c=$ mixture of xylose, maltose, cellobiose; cellob = cellobiose). These were all Gram-negative pleomorphic coccoid or rod-shaped bacteria, sometimes with very irregular shapes. All fermented dextrin, glycogen, maltose and starch. Isolate $5 \times 1 m c 8$ also fermented fructose. The main 


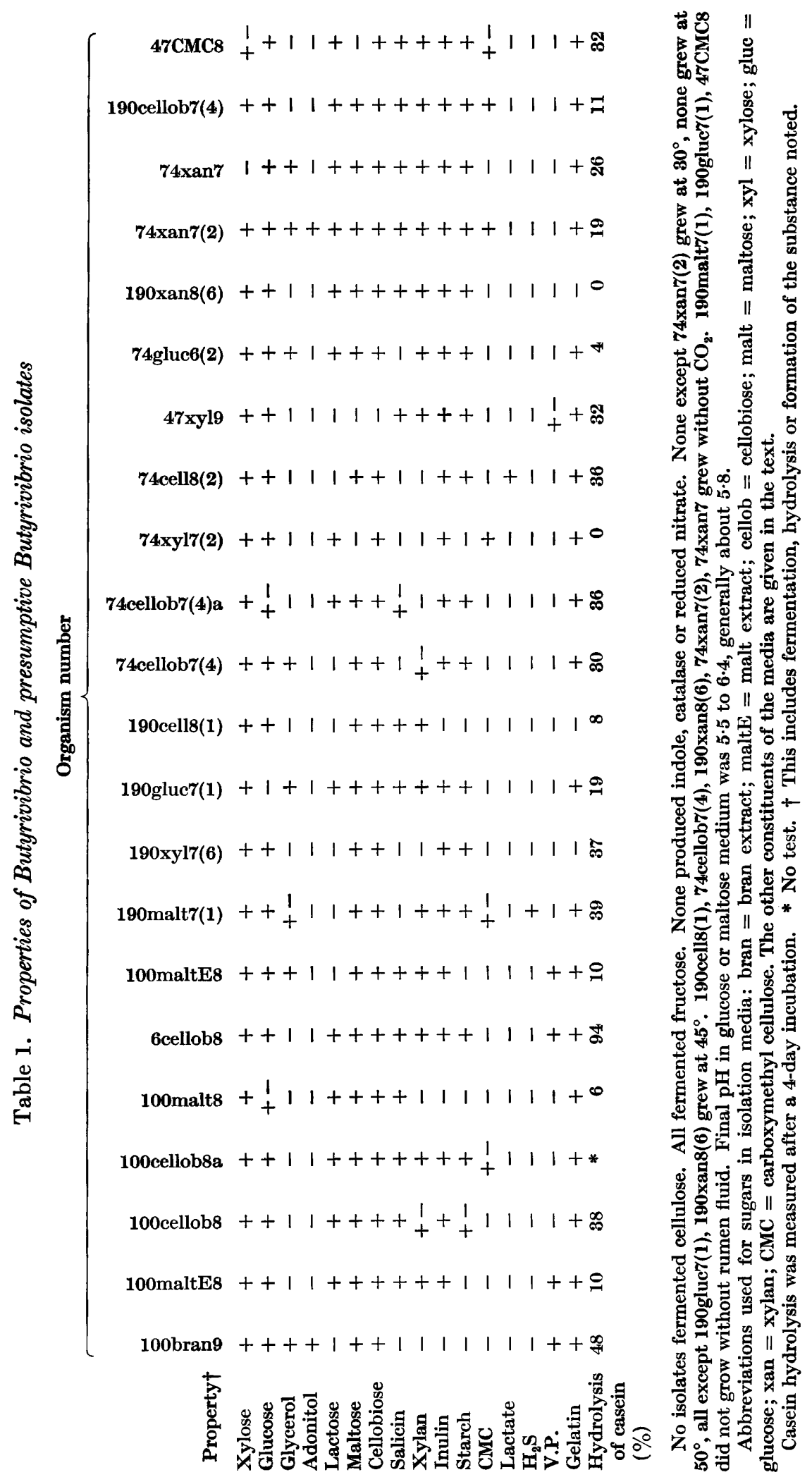


VFA product of maltose fermentation was acetic acid, and the final $\mathrm{pH} c .5 \cdot 7$. The bacteria in this group can be classified as Bacteroides amylophilus (Hamlin \& Hungate, 1956). All isolates except 74gluc8(2) were similar to the type species in requiring $\mathrm{CO}_{2}$ for growth, and all except 47 gluc8 would grow without rumen fluid. Isolate 74gluc8(2) formed $\mathrm{H}_{2} \mathrm{~S}$, and 47 gluc8 reduced nitrate. No strains grew at $30^{\circ}$ and only $5 \times \mathrm{xmc8}, 47 \mathrm{gluc8}$, and 47 cellob9 at $45^{\circ}$. All isolates except 74maltE6 hydrolysed gelatin and the hydrolysis of casein by the isolates (in the order given initially) was $49,78,85,33,60,47,62,54$ and $84 \%$ respectively.

Group 2. Butyrivibrio. The bacteria grouped in Table 1 were all presumptively identified as Butyrivibrio (Bryant \& Small, 1956a). With the exceptions mentioned

Table 2. Properties of presumptive Selenomonas isolates

\begin{tabular}{|c|c|c|c|c|c|c|c|}
\hline \multirow[b]{2}{*}{ Property } & \multicolumn{7}{|c|}{ Organism number } \\
\hline & 6cellob8 & 6 malt 7 & 6 malt7a & 6cellob8a & $\begin{array}{c}\text { 74star- } \\
7(2)\end{array}$ & $\begin{array}{c}\text { 190malt- } \\
\text { E8(1) }\end{array}$ & $\begin{array}{c}\text { 190star- } \\
8(3)\end{array}$ \\
\hline Sorbose & - & - & - & - & + & - & - \\
\hline Glycerol & + & + & + & - & - & - & - \\
\hline Sorbitol & - & - & - & - & + & - & - \\
\hline Lactose & + & + & + & + & + & + & - \\
\hline Cellobiose & + & + & + & + & + & - & + \\
\hline Xylan & +- & - & - & + & + & - & - \\
\hline Inulin & + & - & - & - & + & + & + \\
\hline Starch & +- & +- & + & - & + & + & + \\
\hline Lactate & + & + & + & - & - & - & - \\
\hline Succinate & - & - & - & - & +- & - & - \\
\hline $\mathrm{H}_{2} \mathrm{~S}$ & - & + & + & - & + & - & - \\
\hline V.P. & - & - & + & - & - & - & - \\
\hline $\mathrm{NO}_{3}$ & - & + & + & - & + & - & $*$ \\
\hline Indole & - & - & - & - & - & + & - \\
\hline Growth-rumen fluid & + & - & + & + & + & + & - \\
\hline Growth- $\mathrm{CO}_{2}$ & - & - & - & - & + & - & - \\
\hline Gelatin & + & - & * & + & + & - & - \\
\hline Hydrolysis of casein (\%) & 95 & 90 & 90 & 95 & 84 & 47 & 46 \\
\hline
\end{tabular}

Symbols as in Table 1, with star = starch. All isolates fermented xylose, glucose, fructose, maltose, salicin. No isolates fermented CMC, adonitol, cellulose. Only 190maltE8(1) and $74 \mathrm{star}^{2}(2)$ grew at $45^{\circ}$, the latter also at $50^{\circ}$. Final $\mathrm{pH}$ in glucose was about $\mathbf{5 \cdot 2 .}$

* No test.

later all were Gram-negative curved rods, about $0 \cdot 6 \mu \times 1 \cdot 5 \mu$ in average size, sometimes in chain formation. A number of isolates were motile with a polar flagellum. The principle product of fermentation of glucose, or in one case maltose, was butyric acid. Isolate $47 \mathrm{cmc8}$ is probably a Butyrivibrio, although in morphology it tended to be a stouter and more coccoid rod. Isolate 190cellob7(4) was similar in many properties to Butyrivibrio, but it was more pleomorphic and at times formed straighter rods than the usual Butyrivibrio and these rods formed chains. In morphology and growth it somewhat resembled the two strains of group 4, but differed from them in forming butyric acid, and is best classified here. Isolates 190xan8(6), 74xan7(2), 74xan7 were all broader curved rods than the others with one side straighter, 190xan8(6) was also capsulated, but their general properties fit in with the rest of this group.

Group 3. Selenomonas. The organisms in this group (Table 2) all usually exhibited 
a characteristic Selenomonas morphology and flagellation, varying in size from about 2 to $5 \mu$ in length and from 0.4 to $1 \mu$ in maximum width. However, all isolates tended to form chains at times and the cells in the chains were often straighter rods with rounded ends. The fermentation reactions were generally similar to those of Selenomonas ruminantium (Bryant, 1956), and the three lactate- and glycerol-fermenting isolates could be classified as $S$. ruminantium var. lactyliticas (Bryant, 1956). In VFA fermentation products of glucose the four isolates labelled 6 cellob8 and 6malt7 resembled the type cultures of Bryant in forming mainly propionic and acetic acids. The other three isolates produced butyric acid, with little acetic, and in this respect resembled the atypical $S$. ruminantium strain $\mathbf{B 3 8 5}$ (Bryant, 1956), which is probably a species of Butyrivibrio.

Group 4. Lachnospira. Two isolates were presumptively identified with the new genus Lachnospira described by Bryant \& Small (1956b). These two isolates (74malt$7(1), 74$ cellob6(2)) were similar in being Gram-negative or -variable rods, about $\mathbf{3} \mu$ long, sometimes slightly curved, motile with a polar flagellum and often occurring in chains. They formed a 'woolly' colony in agar and in liquid medium a zoogloeal type of growth which sedimented out. They formed acetic acid from glucose and grew without rumen fluid. In all these properties they resembled $L$. multiparus (Bryant \& Small, 1956 b). They differed from the type culture in some reactions. The other main properties of the two isolates were as follows. Both fermented cellobiose, glycerol (74malt7(1) only weakly), glucose, inulin, lactose, maltose and starch. Neither fermented adonitol, inositol, salicin, cellulose, carboxymethyl cellulose, pectin nor lactate. Isolate 74cellob6(2) fermented melibiose, xylose and xylan; 74malt7(1) formed $\mathrm{H}_{2} \mathrm{~S}$; neither grew without $\mathrm{CO}_{2}$, reduced nitrate nor formed indole; both gave a positive v.P. test and both grew at $45^{\circ}$. The final $\mathrm{pH}$ in glucose medium was 4.7 . Isolate $74 \mathrm{malt7}(1)$ hydrolysed casein to the extent of only about $2 \% ; 74$ cellob6(2) to about $9 \%$ in 4 days; both hydrolysed gelatin.

Group 5. The properties of group 5 are given in Table 3. These bacteria showed similarities in being Gram-negative rods, 0.8-1 $\mu \times 3-5 \mu$, sometimes curved with pointed ends, either singly or in chains, with granulations or polar staining, but often forming chains of straighter cells. In some cases motility, with peritrichous flagella, was seen, but in most cases only an oscillatory movement, or no motion, was found. All formed mainly butyric acid, with some acetic, from glucose or maltose. Growth in liquid medium was zoogloeal or granular. Isolates 190nil7(6) and 190nil7(6)a differed to some extent from the others in being more crescentic, with more definite bipolar staining and also in not hydrolysing gelatin and being only weakly proteolytic on casein. $5 \times$ xmc7, $5 \times$ mc7a and $5 \times m c 8$ were generally less curved than the others and had more rounded ends. The bacteria of this group had some similarity to Lachnospira in growth characteristics in liquid media but formation of butyric acid excludes them from this classification. They are similar to Bacteroides. However, the curved shape and pointed ends of the cells of some of the isolates might preclude them from this group and suggest relationships with the Spirillaceae (in morphology and growth they somewhat resemble Myconostoc gregarium) although B. succinogenes (Bryant \& Doetsch, 1954) can have pointed ends. In the formation of butyric acid from glucose they also differ from all but one strain of rumen Bacteroides so far reported, this latter was found in young calves by Bryant, Small, Bouma \& Chu (1958). 
Group $5 a$ comprised three isolates (190malt7(4), 74starch6(2), 47nil9), and their properties are given in Table 3. Isolates 190malt7(4) and 74starch6(2) were similar in being pleomorphic Gram-negative curved rods, sometimes long and thin with more than one coil $(0.3 \mu \times 9 \mu)$, at other times stouter, straighter and shorter $(0 \cdot 6 \mu \times 2 \mu)$ with rounded ends. Chain formation was common and the cells in some cultures of 74starch6(2) had a twisting movement. Isolate 47 nil9 were generally straighter rods about $1 \mu \times 4 \mu$, more variable in Gram staining. The one isolate

Table 3. Properties of groups 5 and 5 a

\begin{tabular}{|c|c|c|c|c|c|c|c|c|c|c|c|c|c|}
\hline \multirow[b]{2}{*}{ Property } & \multicolumn{10}{|c|}{ Group 5. Organism number } & \multicolumn{3}{|c|}{$\begin{array}{c}\text { Group } 5 a \\
\text { organism } \\
\text { number }\end{array}$} \\
\hline & 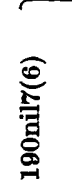 & 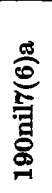 & 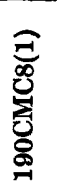 & 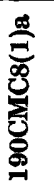 & 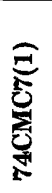 & 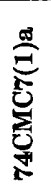 & 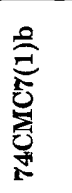 & 댏 & है & 里 & 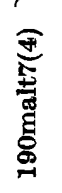 & 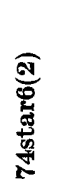 & 욜 \\
\hline Xylose & + & + & + & + & + & + & + & - & + & + & + & - & - \\
\hline Glucose & + & + & + & + & - & - & + & + & + & + & + & + & + \\
\hline Fructose & + & + & + & + & + & + & + & + & + & + & - & + & + \\
\hline Glycerol & +- & - & + & + & - & + & + & + & - & - & - & - & - \\
\hline Adonitol & + & - & - & - & + & - & + & - & - & - & - & - & - \\
\hline Inositol & - & - & - & - & - & - & - & - & - & - & + & - & - \\
\hline Maltose & + & + & + & + & + & + & + & + & + & + & + & + & + \\
\hline Lactose & + & - & + & + & + & + & + & + & + & + & +- & + & + \\
\hline Cellobiose & + & + & + & + & + & + & + & + & - & + & - & + & + \\
\hline Salicin & + & + & + & + & + & + & + & - & + & + & + & + & + \\
\hline Xylan & + & + & + & + & + & + & + & + & - & +- & - & - & - \\
\hline Inulin & - & + & + & + & + & + & + & + & + & + & + & + & - \\
\hline Starch & +- & - & + & + & - & - & +- & + & + & + & + & + & + \\
\hline CMC & - & - & + & + & - & - & + & - & +- & +- & - & - & - \\
\hline Cellulose & +- & - & + & - & - & - & - & - & - & - & - & - & - \\
\hline Lactate & + & - & + & - & - & - & + & - & - & - & + & - & - \\
\hline Succinate & - & - & - & - & - & - & - & + & +- & +- & - & - & - \\
\hline $\mathbf{H}_{2} \mathrm{~S}$ & + & - & - & + & - & - & + & + & - & - & - & - & - \\
\hline Indole & - & - & - & - & - & - & - & - & - & - & - & +- & - \\
\hline Gelatin & - & - & + & + & + & + & + & + & + & + & - & + & - \\
\hline Hydrolysis of & 4 & 14 & 45 & 40 & 51 & 65 & 40 & 62 & 57 & 69 & 68 & $\mathbf{0}$ & $\mathbf{0}$ \\
\hline
\end{tabular}

Symbols as in Table 1 and 2 with nil = no carbohydrate.

Group 5. V.P. and nitrate reduction tests were all negative. No isolate grew at $30^{\circ}$ or $50^{\circ}$, strains 190 nil7(6)a, $190 \mathrm{CMC8}(1)$ a, $74 \mathrm{CMC7}(1), 7_{4 \mathrm{CMC}}(1)$ a grew at $45^{\circ}$. All except $190 \mathrm{CMC8}(1)$ and 74CMC7(1) grew without $\mathrm{CO}_{2}$ and 5xmc7 grew without rumen fluid. All produced butyric acid from glucose or maltose. Final pH varied from $4 \cdot 6$ to $5 \cdot 9$ with different isolates and was generally about 5.0.

Group 5a. V.P. and nitrate tests were negative. No isolate grew without $\mathrm{CO}_{2}$ and $190 \mathrm{malt7}(4)$ would not grow without rumen fluid. None grew at $30^{\circ}$ or $50^{\circ}$, all grew at $45^{\circ}$. All produced acetic acid from glucose, final $\mathrm{pH}$ was $5 \cdot 8$ to $6 \cdot 4$.

tested (190malt7(4)) produced succinic acid from glucose and all three produced mainly acetic amongst the VFA products of glucose fermentation. These isolates were tentatively classified as Bacteroides ruminicola (Bryant et al. 1958).

Groups 6, 6a, 6b. The organisms in this section are grouped under one main heading as they were all rather pleomorphic, Gram-negative or -variable, oval cocci or coccobacilli. They have been subdivided on the basis of morphology and also on their fermentation products. However, fermentation reactions and to some 


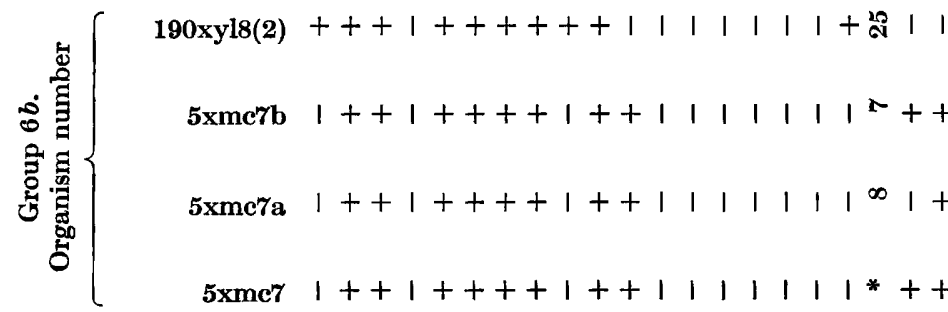

74malt7(6)a $1+++1++11+111+1+++\infty++$ I90gluc9(24) $11_{+}^{1}+1+111+11111++100$ 74maltr(6) $\begin{gathered}1 \\ +\end{gathered}+\begin{gathered}1 \\ 1 \\ +\end{gathered}+1+1+111+1+++=1+$ 74nilr(6)a $+1+1111+\frac{1}{+} 111+111+1011$ 6 malt9a $+++1++++\frac{1}{+}++111+11+\infty 11$

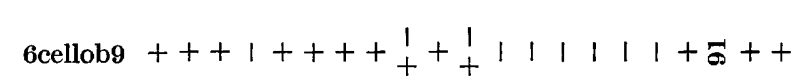
74cellob7(4) $+++1+++++++1,1,1,+$, $1+$ त

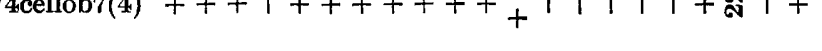
74nil7(6) $1++111+\frac{1}{+} 111 \frac{1}{+}+11111011$

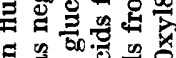
74nilf(6) $1+11++1+1+111110$

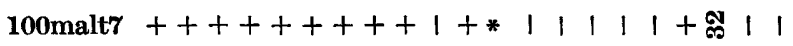
6 maltE8 $++11+++++++* 11+11+\infty 1++$ 过

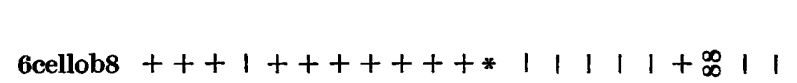

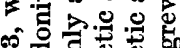

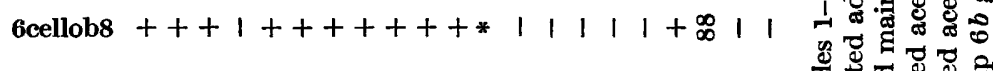

总 


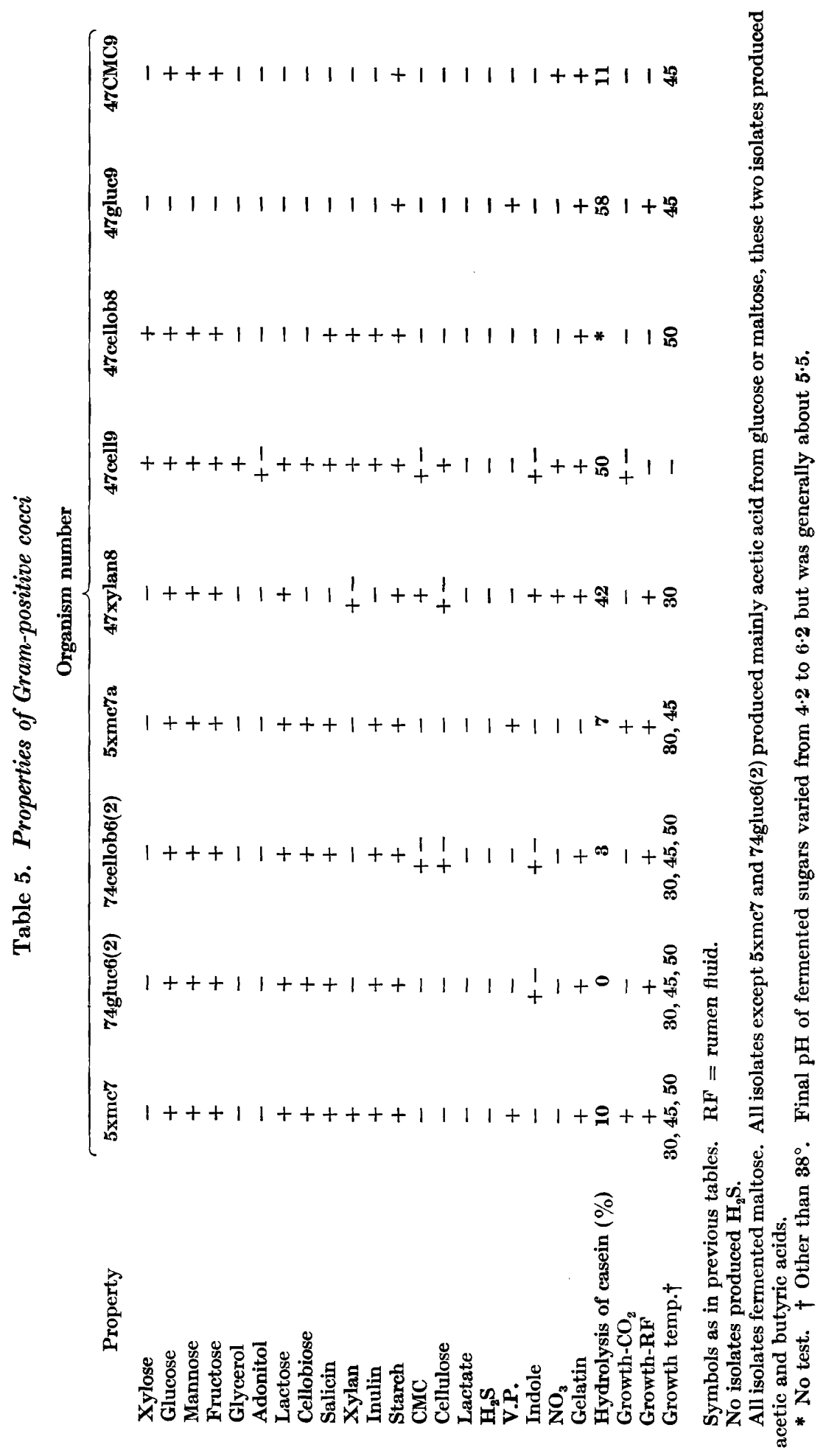


extent morphology, varied amongst members of the groups and it is probable that a number of species are represented in each group. Their properties are given in Table 4.

Group 6 were small Gram-negative or -variable oval cocci 0.5-1 $\mu$ long, sometimes occurring in pairs, but generally singly. They formed mainly acetic acid from glucose or maltose.

Group 6'a. This was a group of Gram-negative or -variable cocci or coccobacilli, all exhibiting some pleomorphism and variation in size, but in general, being about 0.5-1 $\mu$ long. All produced propionic as well as acetic acid from glucose or maltose.

Group $6 b$. The first three members of this group were all similar Gram-variable coccobacilli, rather larger than those of groups 6 and $6 a$, being about $0.9 \mu \times 2 \mu$. They were also facultatively anaerobic. Isolate $190 x y l 8(2)$ was predominantly Gram-negative, had more tendency to chain formation and the cells were about $0.9 \mu \times 1 \cdot 3 \mu$. All the isolates in this group produced a mixture of acetic and butyric acids from glucose, and all were motile with a polar flagellum.

Some of the isolates of groups $6,6 a, 6 b$ resembled Eubacterium ruminantium (Bryant, 1959), but there seems in general to be no complete basis for including these groups in any so far named groups of rumen bacteria.

Group 7. These were all small Gram-positive cocci, about $1 \mu$ diameter occurring singly or in groups and, apart from the three mentioned above, they were the only facultatively anaerobic bacteria amongst those described in this paper. Their properties are given in Table 5. As these isolates differed in reactions it seems likely that this group could be further subdivided.

Urea hydrolysis. All the bacteria isolated were tested for ammonia production in a medium containing urea but no ammonium salts. Except for one isolate (Grampositive coccus, 47cell9) there was little change in the ammonia concentration in the media (there was always a small amount of ammonia present from the rumen fluid and other constituents) and any increase in concentration was very small compared with the amount of urea present. In some cases there was an uptake of ammonia. There was thus no evidence for any definite hydrolysis of urea by any of the strictly anaerobic bacteria isolated.

Zones of proteolytic activity. Proteolytic activity of colonies growing in roll tubes of medium containing casein was shown by a clear zone surrounded by a more opaque ring in the somewhat cloudy medium and this area gradually spread with growth of the colony.

\section{DISCUSSION}

It was noted in earlier experiments that the carbohydrates included in the medium had an effect on the types of proteolytic bacteria growing and the apparent degree of proteolysis, but more extended observations showed that this was not as specific as was at first thought. In some cases the influence was due to provision of a suitable substrate for growth, as in the case of Bacteroides amylophilus which grew well in a maltose-containing medium. Some of the carbohydrates used may have also aided the growth of recognizably proteolytic bacteria by somewhat suppressing the rapid growth of other bacteria which occurred on more easily utilized substrates such as glucose.

In many cases the extent of hydrolysis of casein to trichloroacetic acid-soluble 
products was not high, and in some cases casein hydrolysis seemed to be an unstable property, decreasing on continued subculture. There was also evidence that the enzymes were to some extent adaptive as rapid subculture in a casein-containing medium in some cases led to a greater degree of hydrolysis of the protein. It is thus probable that the comparatively limited hydrolysis of casein exhibited by many of the bacteria is not completely indicative of their proteolytic activity in the rumen, where a constant amount of protein is added to what is, in effect, a continuous culture of the organisms.

In the earlier work (Blackburn \& Hobson, $1960 \mathrm{~b}$ ), facultatively anaerobic Grampositive cocci occurred in almost all the experiments and they have also been isolated in the present tests, although attention was focused in these experiments on the anaerobic types. The bacteria other than cocci isolated here were all found over a long period in the different sheep and must also be a stable part of the rumen proteolytic flora. Bacteroides amylophilus was especially prevalent in sheep being fed a ration high in starch. The types isolated in many cases belong to groups of bacteria already shown to be of importance in the ruminal breakdown of other feedstuff constituents and to be widely distributed in ruminants. These results would support the general findings that the proteolytic activity of rumen contents does not vary greatly with variations in diet.

Fulghum, King \& Moore (1958) reported the isolation of non-sporeforming anaerobic bacteria from the bovine rumen which caused clearing in a medium containing milk as casein source, and Bryant et al. (see review by Bryant, 1961) have noted that a number of their isolates of bovine rumen bacteria, especially Bacteroides ruminicola, some Butyrivibrio strains and some Eubacterium strains, hydrolysed casein and/or gelatin during biochemical tests. These results fit in with the present data, and all the results so far indicate that there is no one specific type of proteolytic bacterium in the rumen, but that proteolytic activity is a variable property associated with particular strains of species generally active in other feedstuff breakdown. It is possible that some non-proteolytic strains may contain peptidases which will act during the complete breakdown of feedstuff protein in the rumen.

The fact that no definite hydrolysis of urea was found is again in accord with results of attempts to isolate anaerobic urease-producing bacteria from the rumen. Only one type has so far been isolated and this was a Gram-positive rod related to Lactobacillus bifidus (Gibbons \& Doetsch, 1959).

The authors would like to thank Mr J. McIntosh for skilled technical assistance and Mr W. Smith for the fatty acid analyses.

\section{REFERENCES}

Blackburn, T. H. \& Hobson, P. N. (1960a). Proteolysis in the sheep rumen by whole and fractionated rumen contents. J. gen. Microbiol. 22, 272.

Blackburn, T. H. \& Hobson, P. N. (1960b). Isolation of proteolytic bacteria from the sheep rumen. J. gen. Microbiol. 22, 282.

BlackBurn, T. H. \& Hobson, P. N. (1960c). Breakdown of protein and proteolytic activity in the sheep rumen at different times after feeding. J. gen. Microbiol. 22, 290.

Bryant, M. P. (1956). The characteristics of strains of Selenomonas isolated from bovine rumen contents. J. Bact. 72, 162.

Bryant, M. P. (1959). Bacterial species of the rumen. Bact. Rev. 23, 125. 
Bryant, M. P. (1961). The nitrogen metabolism of pure cultures of ruminal bacteria. Proc. Ruminant Nutrition Conference, April 1961. U.S.D.A. reprint A.R.S. 44-92, April 1961.

Bryant, M. P. \& Doetsch, R. N. (1954). A study of actively cellulolytic rod-shaped bacteria of the bovine rumen. J. Dairy Sci. 37, 1176.

BryanT, M. P. \& Small, N. (1956a). The anaerobic monotrichous butyric acid-producing curved rod-shaped bacteria of the rumen. J. Bact. 72, 16.

Bryant, M. P. \& Small, N. $(1956 b)$. Characteristics of two new genera of anaerobic curved rods isolated from the rumen of cattle. J. Bact. 72, 22.

Bryant, M. P., Small, N., Bouma, C. \& ChU, H. (1958). Bacteroides ruminicola n.sp. and Succinimonas amylolytica the new genus and species. J. Bact. 76, 15.

Conway, E. J. (1957). Microdiffusion Analysis and Volumetric Error, 4th ed. London: Crosby Lockwood and Co. Ltd.

Fulghum, R. S., King, K. W. \& Moore, W. E. C. (1958). Development and comparison of media for the isolation of proteolytic bacteria from the rumen. Bact. Proc. p. 22.

Gibbons, R. J. \& Doetsch, R. N. (1959). Physiological study of an obligately anaerobic ureolytic bacterium. J. Bact. 77, 417 .

Hamlin, L. J. \& Hungate, R. E. (1956). Culture and physiology of a starch-digesting bacterium (Bacteroides amylophilus n.sp.) from the bovine rumen. J. Bact. 72, 548.

Howard, B. H., Jones, G. \& Purdom, M. R. (1960). The pentosanases of some rumen bacteria. Biochem. $J .74,173$.

Hungate, R. E. (1950). The anaerobic mesophilic cellulolytic bacteria. Bact. Rev. $14,1$. 